\title{
A experiência dos diários reflexivos no processo formativo de uma Residência Multiprofissonal em Saúde da Família
}

\author{
Filipe Guterres Venancio Costa de Oliveira ${ }^{1}$ \\ Maria Alice Pessanha de Carvalho \\ Margareth Rose Gomes Garcia ${ }^{3}$ \\ Simone Santos Oliveira ${ }^{4}$
}

\section{Introdução}

A Residência Multiprofissional em Saúde da Família da Escola Nacional de Saúde Pública da Fundação Oswaldo Cruz (Ensp/Fiocruz) adota, como um de seus instrumentos metodológicos, o diário reflexivo. Neste artigo, buscaremos compreender melhor esse instrumento, baseados na experiência de acompanhamento de um grupo de residentes no decorrer de dois anos, tempo de duração do curso.

Em 2003, a escola desenvolveu uma reforma curricular denominada ENSP em Movimento, pautada na construção de programas de formação baseados em competências profissionais identificadas com as necessidades do Sistema Único de Saúde (SUS). Objetivava construir um novo modelo político pedagógico, repensando as estratégias de ensino e incorporando o mundo do trabalho como eixo fundamental na produção do conhecimento e na definição de demandas educacionais.

Em 2005, o curso se chamava Especialização em Saúde da Família nos moldes da Residência, com parcerias da Secretaria Municipal do Rio de Janeiro - como cenário de aprendizagem, a sua rede de Atenção Primária de Saúde, especificamente as estruturas da Estratégia de Saúde da Família/ESF denominadas de módulos -, e do Núcleo Regional do Ministério da Saúde no Rio de Janeiro (NERJ) - mediante financiamento das bolsas de residência.

O curso foi fundamentado: na metodologia de construção curricular baseada em competência, na concepção do profissional reflexivo e na articulação trabalho e formação. Este currículo, em vigor, apresenta três áreas: Organização do Processo de Trabalho; Cuidado à Saúde: individual, coletivo e familiar; e Educação e Formação em Saúde. Articula os seguintes princípios orientadores da residência multiprofissional: integralidade e interdisciplinaridade; conceito ampliado de saúde; multiprofissionalidade; noção de rede de cuidados/cadeia do cuidado e educação permanente em saúde (Carvalho, Garcia, Seidl, 2006).

A política pública da Estratégia da Saúde da Família (ESF) aposta na transformação da atual realidade do sistema de saúde, através da ação da equipe multiprofissional, com destacado envolvimento da comunidade. Pode-se, dessa forma, oferecer uma assistência individual de qualidade, junto a uma assistência

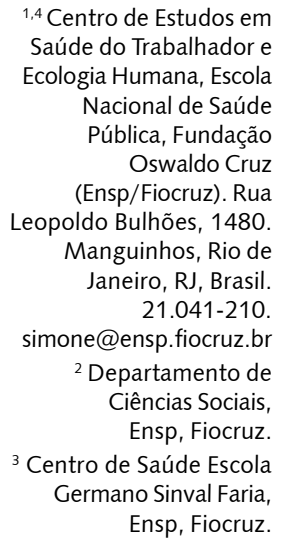

${ }^{1,4}$ Centro de Estudos em Saúde do Trabalhador e Ecologia Humana, Escola Nacional de Saúde Pública, Fundação Oswaldo Cruz (Ensp/Fiocruz). Rua Leopoldo Bulhões, 1480. Manguinhos, Rio de Janeiro, RJ, Brasil. 21.041-210.

simone@ensp.fiocruz.br

${ }^{2}$ Departamento de Ciências Sociais, Ensp, Fiocruz.

${ }^{3}$ Centro de Saúde Escola Germano Sinval Faria, Ensp, Fiocruz. 
clínica resolutiva, baseadas nos parâmetros da promoção da saúde. Estas ações, que buscam favorecer a atenção e o cuidado coletivo, pretendem colaborar com a transformação da realidade local, para superar desigualdades e iniquidades sociais. Em seus documentos de referência, a ESF aponta como seus objetivos: a) humanização das práticas de saúde por meio do estabelecimento de um vínculo entre os profissionais e a população; b) a democratização do conhecimento do processo saúde-doença e da produção social da saúde; c) o desenvolvimento da cidadania, levando a população a reconhecer a saúde como direito; d) a estimulação da organização da comunidade para o efetivo exercício do controle social (Brasil, 2006).

A análise que empreendemos aqui se baseia, sobretudo, no uso do Diário Reflexivo, tendo como referência sua origem no diário de campo da antropologia e no portfólio reflexivo da educação. $\mathrm{Na}$ antropologia, o diário de campo se configura como um "instrumento depositário de notas, impressões, observações, primeiras teorizações, mapas, esboços, desabafos, entrevistas e garatujas de informantes" (Magnani, 1997, p.8). Auxilia na formulação de hipóteses, direciona a pesquisa, permite visualizar retrospectivamente as lacunas, e é motivador do diálogo e de resgate do vivido. Já o portifólio reflexivo é definido como uma narrativa de caráter biográfico. Segundo Sá-Chaves (2005), o portifólio permite o acesso, não só aos conhecimentos vivenciados, mas, também, aos significados atribuídos, pelo autor, às circunstâncias em que ocorreram, e ao modo como os significados reconstroem as práticas.

Como ressaltam Caprara e Landim (2008), nos últimos anos, houve um interesse grande pelos métodos qualitativos na pesquisa em saúde. Muito disso se deve a novos paradigmas que se estabeleceram dentro dessa área de conhecimento, na qual passaram a figurar preocupações com o sujeito como um todo - lembrando que a saúde não é algo que se possa cuidar isoladamente, ao se entender que ela está ligada a todos os aspectos da vida. A Residência está de acordo com essa perspectiva na medida em que seu processo de ensino-aprendizagem se orienta pelo sentido da promoção da saúde, que considera a saúde como um conjunto de aspectos, e não apenas como ausência de doença. A formação do residente busca criar condições para que ele seja capaz de diagnosticar, planejar, intervir e avaliar as questões de saúde que acometem sujeitos, famílias e comunidades. Sendo assim, esta formação deve apontar para a compreensão da realidade de saúde da comunidade, o que exige que se interaja com as complexas tramas sociais, econômicas e culturais inerentes aos grupos (Santos, 2010).

Para tanto, são necessários enfoques menos fragmentados, abertos à diversidade e à complexidade do cotidiano, em que a interdisciplinaridade é uma exigência imprescindível para se abordarem as questões relativas à saúde das populações e dos indivíduos. Compreender que cada pessoa está inserida em redes, estruturas, formas de pensamento coletivas, que marcam e orientam seu comportamento, é fundamental para se encontrarem soluções para as causas do sofrimento, uma vez que elas estão para além do corpo biológico (Raynaut, 2006).

\section{A etnografia}

O estudo realizado pelos residentes nas comunidades é um trabalho de campo com características da etnografia. No campo da antropologia, a figura do diário de campo surgiu com o antropólogo Bronislaw Malinowski que, na introdução de seu clássico estudo "Os Argonautas do Pacífico Ocidental" (1922), marcou a história da antropologia moderna ao propor uma nova forma de etnografia, envolvendo detalhada e atenta observação participante, apesar de o próprio nunca ter utilizado o termo. $\mathrm{Na}$ introdução de seu livro, o autor chama a atenção para o fato de que, nas ciências físicas e químicas, sempre há um registro exato das experiências que realizou, dos instrumentos utilizados, das observações, e como elas foram conduzidas, do seu número e da quantidade de tempo que lhes foi dedicado. Em ciências não exatas, isto não pode ser feito de forma tão rigorosa; relata-se o melhor possível para informar ao leitor sobre as observações e experiências. Segundo Malinowski (1997, p.30):

Lamentavelmente, na Etnografia, onde a apresentação desinteressada dessa informação se torna talvez ainda mais necessária, isto nem sempre tem sido devidamente explicitado e muitos autores limitam-se a apresentar os dados adquiridos, fazendo-os emergir, perante 
nós, a partir da mais completa obscuridade, sem qualquer referência aos processos para a sua aquisição.

A partir dessa percepção, o autor iniciou sua preocupação em estabelecer regras para dar à etnografia a consolidação necessária para se transformar em um método. As primeiras etnografias eram feitas baseadas em questionários; os antropólogos não iam ao campo, apenas mandavam os questionários que, em geral, eram aplicados por missionários, os quais, na maioria das vezes, sabiam a língua nativa. Era comum ainda que os etnógrafos anteriores a Malinowski, quando iam a campo, se mantivessem numa postura distante do grupo. Mas ele ressalta a importância da participação nas atividades diárias, bem como o aprendizado da língua e o isolamento. A figura do diário de campo, importante instrumento de registro do etnógrafo, ganha destaque justamente a partir desses novos princípios.

Uma parte expressiva do ofício do etnógrafo reside na construção do diário de campo. "Esse é um instrumento que o pesquisador se dedica a produzir, dia após dia, ao longo de toda a experiência etnográfica" (Weber, 2009, p.158). Nele deverão estar contidos todos os elementos que, posteriormente, serão usados pelo etnógrafo para construir/consolidar suas reflexões. Por isso, é importante, segundo Florence Weber, registrar os eventos observados ou compartilhados, os discursos e as posições dos entrevistados, bem como as relações que se criaram entre o pesquisador e os pesquisados. Mas o que nos interessa efetivamente no trabalho desta autora é a distinção que ela faz entre os diários que são confeccionados durante uma pesquisa de campo. São três os tipos de diário: um diário de campo específico da etnografia, aquele que já apresentamos anteriormente; um diário de pesquisa, o qual não se destinaria necessariamente a etnografias; e um diário "íntimo", no qual estariam contidos os relatos de cunho pessoal do pesquisador, como podemos ler em Weber (2009, p.158-9):

[...] três tipos de diários: um diário de campo específico da etnografia; um diário de pesquisa, tal como poderia desenvolver um historiador ou um filósofo; e um "diário íntimo". Nesse último caso, conforme o modelo dos diários autobiográficos em que são depositados os humores e as emoções de seu autor. É no diário de campo que se exerce plenamente a "disciplina" etnográfica: deve-se aí relacionar os eventos observados ou compartilhados e acumular assim os materiais para analisar as práticas, os discursos e as posições dos entrevistados, e também para colocar em dia as relações que foram nutridas entre o etnógrafo e os pesquisados e para objetivar a posição de observador. É, pois, o diário de pesquisa de campo que permitirá não somente descrever e analisar os fenômenos estudados, mas também compreender os lugares que serão relacionados pelos observados ao observador e esclarecer a atitude deste nas interações com aqueles.

Torna-se pertinente perguntar se o recente e crescente uso da etnografia na pesquisa em saúde não se caracterizaria quase como uma distorção de suas premissas originais, configurando-se no que se poderia chamar de observação de "tipo" etnográfico (Caprara, Landim, 2008). Sem dúvida, o estudo empregado pelos residentes é do "tipo" etnográfico, como dizem as autoras, e o que os aproxima é a forma como se dá sua inserção nesse campo. As equipes de residentes multiprofissionais (enfermeiro, cirurgião dentista, nutricionista, psicólogo e assistente social) são inseridas no campo através de cooperação com os módulos da Estratégia de Saúde da Família. Assim, seu dia a dia no campo é composto pela vivência da rotina desses profissionais, seja nas visitas domiciliares, onde têm a oportunidade de conhecer melhor o território adstrito, os moradores, os hábitos da comunidade, seja nos atendimentos no módulo, em que cada um auxilia de acordo com a sua formação. Isso nos leva a acreditar que, se esse estudo é de um tipo etnográfico, é justamente por essa observação aplicada pelos residentes durante o tempo em que atuam no módulo e na comunidade, que, pelas suas características, é um trabalho de campo.

Não há, contudo, como em etnografias tradicionais, a figura de um informante, nem mesmo a preocupação em se entender certos códigos e costumes que perpassam aquela comunidade. Pode-se dizer, de maneira simples, que tudo o que é observado e considerado relevante é aquilo que, de 
alguma forma, pode afetar a saúde do sujeito. Sabemos também que muitos são os aspectos que interferem na saúde de uma pessoa, e, pensando assim, é cabível imaginar que tudo deve ser observado para que se tenha uma compreensão ampla, a mais completa e próxima possível daquela comunidade. Mas o que queremos ressaltar é que, ao se tratar de um olhar voltado para a saúde, muitos pontos indispensáveis para uma etnografia poderão ser deixados de fora nesse trabalho. Esse campo estudado pelos residentes está de acordo com a maioria dos trabalhos de campo realizados hoje em dia. Já não se fazem mais etnografias exclusivamente sobre as chamadas comunidades primitivas, como, em geral, faziam os antigos antropólogos. Hoje, o campo está muito mais próximo, e cada vez mais se opta por realizar estudos de objetos familiares, o que cria dificuldades, pois, nesses casos, normalmente, é preciso desnaturalizá-los para, então, conseguir torná-los familiar.

\section{Observação participante e o diário reflexivo}

Dessa forma, a observação participante empreendida pelos residentes, no trabalho de campo, é acompanhada de registros nos diários reflexivos.

Os residentes devem apresentar mensalmente o diário, relatando seu cotidiano nos cenários de aprendizagem. É um relato espontâneo das observações, sentimentos, impressões, dificuldades, possibilidades, potencialidades que o aluno observa e registra durante o seu processo desenvolvido no território. O residente dialoga consigo mesmo, com o processo de trabalho e com sua aprendizagem. Esse instrumento tem três funções pedagógicas principais. A primeira é armazenar todas as informações possíveis relacionadas à comunidade e seu território, possibilitando a reflexão posterior acerca do que foi observado, e permitindo também que a coordenação e os docentes tenham uma fonte de informações acerca das necessidades da aprendizagem. A segunda é servir como um espaço para os alunos registrarem mais cuidadosamente sua própria prática e da equipe, com os vários aspectos que a permeiam, buscando, na orientação, a articulação entre teoria e prática. A terceira é promover a competência narrativa: conjunto de habilidades requeridas para reconhecer, absorver, interpretar a serem mobilizadas pelas histórias que se ouve ou lê (Dolores, Peixinho, 2006).

A concepção construtivista de uma nova filosofia de formação, definida por Freire (1999, p.77) como "capacidade de aprender, não apenas para nos adaptarmos a realidade, mas, sobretudo, para transformar, para nela intervir, recriando-a", está nas bases teóricas da Residência. Assim, essa formação necessita de instrumentos apropriados para alcançar seus objetivos, e o diário reflexivo se torna fundamental nesse processo.

O diário também é baseado na experiência do portfólio reflexivo, que já é adotado em várias áreas de formação profissional, cumprindo um papel importante como estratégia que potencializa a construção do conhecimento de forma reflexiva, com vista a uma progressiva emancipação dos sujeitos em formação. Silva e Sá-Chaves (2008, p.723) apontam que: "a utilização da estratégia portfólio reflexivo responde, em grande medida, a esta 'nova' filosofia de formação". Seu uso permite, a quem o elabora, uma reflexão continuada acerca das múltiplas dimensões da prática, é um espaço de questionamento sistemático sobre a prática em situações de trabalho. Considera-se ainda que "a apropriação dos saberes não pode se distanciar dos valores e afetos que tornam significativa a experiência" (Sordi, Silva, 2010, p.948), reforçando o espírito de colaboração entre os residentes. Na Residência, contudo, essa ferramenta ganha novas formas na apropriação pelos residentes.

O diário reflexivo se encaixa nesse trabalho também como um diário de campo, pois há necessidade de observação das características do espaço geográfico para melhor se compreenderem as condições, situações e estilos de vida. Os residentes devem realizar esse processo de maneira minuciosa e, nesse ponto, o registro torna-se um importante auxílio, pois, como fazem os etnógrafos, a qualquer momento, eles podem retornar e refletir sobre uma determinada questão. Dessa forma, o trabalho empreendido por eles nos territórios, além do caráter profissional, é também um trabalho de campo que envolve entender as dinâmicas de funcionamento daquele local, bem como conhecer as pessoas que fazem parte daquele todo.

Portanto, a maior diferença entre os dois está no seu conteúdo. O diário, como já dito, segue características muito próximas às de um diário etnográfico, com contornos mais detalhados da 
observação feita em campo. O portfólio, por sua vez, se direciona mais a registrar as etapas de um processo.

No caso da Residência, esse diário exerce, para os orientadores, o mesmo papel que uma etnografia exerce para o seu leitor. Transmite a ele a sensação de estar no local, vivenciando tudo aquilo que está ali descrito. Por isso mesmo, podemos concluir que o diário reflexivo deve ser confeccionado com os mesmos cuidados que um diário de campo tradicional. Quanto mais detalhes da observação estiverem ali presentes, mais material os alunos terão para suas reflexões durante as orientações; oportuniza debater as questões que venham a surgir do embate permanente entre o que aprendem na teoria e o que vivenciam na prática, ou, mesmo, para a confecção do trabalho de conclusão de curso.

\section{A experiência}

Acompanhamos, ao longo do decorrer de uma Residência, período em torno de dois anos, uma equipe multiprofissional (enfermeira, dentista e psicólogo) de três residentes atuantes em um módulo de ESF, inseridos em comunidade pertencente ao conjunto de favelas conhecido como Complexo do Alemão, no subúrbio do Rio de Janeiro. Na análise dos diários, utilizaremos as letras A, B, C para distinção dos três relatos.

Nosso ponto de partida foram às reuniões de orientação que ocorriam semanalmente (exceto na primeira semana do mês, devido à reunião de turma). A reunião de orientação é um espaço no qual os residentes se encontram com seu orientador acadêmico/docente/tutor, para exporem seus questionamentos diante da complexa relação teoria-prática. As aflições do trabalho em campo e ideias que pretendem pôr em prática junto à equipe do módulo são alguns dos elementos que permeiam esse momento. Esse espaço é aberto à discussão e, por isso, não há recomendação para que siga um roteiro, de forma que esse irá se constituindo de acordo com as necessidades e demandas que apareçam. $O$ diário reflexivo era o principal suporte para reuniões de orientação.

A partir da análise dos diários reflexivos, identificamos como esses são elaborados de maneiras diferentes, deixando claro que cada residente apresentou necessidades particulares e únicas no seu processo de formação. Em um primeiro momento, os diários foram parecidos, contendo relatos de casos da comunidade e descrições detalhadas das atividades em campo. Especialmente por se tratar do primeiro contato com a comunidade, os primeiros diários traziam uma riqueza de detalhes, do olhar aguçado dos residentes em busca de melhor apreender a comunidade e o módulo em que estavam inseridos. Posteriormente, foi possível perceber as peculiaridades de cada residente. As características de cada um se estenderam por todos os diários escritos ao longo dos dois anos. No segundo mês, começaram a aparecer as expectativas e preocupações com o trabalho no Módulo, além das primeiras impressões vindas do relacionamento mais prolongado com a equipe. Apareceu, também, uma mudança na forma de organização do diário do residente $C$, que optou por dividi-lo em temas, e não mais por dias ou semanas, como vinha sendo feito. Essa nova organização fez com que o diário perdesse um pouco em detalhes no relato de casos, mas, em compensação, os anseios pessoais do residente ganharam destaque. A partir do terceiro mês, surgiram duas características comuns entre eles: as angústias do processo de trabalho e a redução no tamanho dos diários, variando, agora, entre quatro e seis páginas (anteriormente, a média era de dez páginas). Porém, apesar dessas características comuns, foi também a partir desse momento que cada residente começou a ter um estilo mais definido de organização de seu diário, o que se refletiu na maneira como os temas são abordados. O residente A apresentou seus relatos normalmente seguidos por um questionamento ou reflexão, questionamentos sobre a relação entre a teoria e a prática; o residente $B$ foi mais pessoal, demonstrando suas emoções e impressões, e o residente $C$, com o diário dividido por tópicos, foi um meio-termo entre os dois primeiros, mesclou reflexão teórica com suas impressões pessoais.

Essas características, demonstradas já nos primeiros meses, se prolongaram durante todo o decorrer da Residência, não só nos diários, como também nas reuniões de orientação, quando as discussões muitas vezes seguiam um padrão bem semelhante ao que estava escrito, com cada um dos residentes expondo, em suas falas, as mesmas características. As reuniões de orientação do grupo de residentes mencionados neste artigo sempre contaram com a ampla participação dos conteúdos dos diários. A 
orientadora lia os diários antes, de forma que, ao encontrar os residentes, ela já estava ciente das questões por eles relatadas. As discussões não ficavam restritas ao conteúdo escrito, muitos fatos novos surgiam no processo de orientação. Mas era a partir dos relatos que as discussões eram balizadas e muitas questões suscitadas e trazidas para as reuniões.

Diante de um curso que adota, como referência de aprendizagem, a concepção construtivista, que identifica o aluno como construtor de conhecimento, o Diário atua justamente como parte dessa construção, já que é uma ferramenta que auxilia na intervenção da realidade.

O grupo de residentes aqui estudados deixou clara a importância do diário no processo de formação, uma vez que as reuniões de orientação se baseavam nos relatos. As discussões a respeito de fatos ocorridos no cotidiano ganhavam elementos novos a partir das anotações, pois, muitas vezes, a própria memória dos residentes apagava aspectos importantes de serem levantados. Além disso, em muitos momentos, foi possível retornar a determinados pontos do trabalho em campo graças a releituras de todo o material. A partir dessas reflexões, os residentes, além de aprenderem com sua própria prática de trabalho, enfrentando os conflitos e problemas, buscam construir saídas (Sordi, Silva, 2010).

Percebeu-se que, quando um determinado assunto era relevante, este aparecia nos três diários. Alguns casos exemplificam bem isso. Um que chama bastante atenção é o de uma moradora da comunidade que tem problemas mentais e com a qual a equipe do módulo nunca conseguiu um bom relacionamento, ocasionando dificuldades no seu tratamento. A equipe de residentes começou então a dar uma atenção especial a ela e sua família. No começo, os relatos sobre este caso eram tímidos, mais no sentido de contarem um pouco da história da paciente e de como eles chegaram até ela. Mas logo, com o desenrolar da história, começaram a aparecer questionamentos a respeito da sua conduta. Um deles ressalta, inclusive, se o que estavam fazendo era assistência ou paternalismo. Os relatos indicavam, ainda, os problemas com a preceptoria de território. Se a princípio eram simples comentários, logo se tornaram contundentes reclamações a esse respeito, o que foi, por inúmeras vezes, alvo de longas discussões durante as orientações. Os relatos das dificuldades do dia a dia davam força e veracidade à fala dos alunos, deixando claro que aquele era um problema que realmente os estava afligindo e que precisava ser resolvido para não prejudicar a continuidade do trabalho. E, sempre quando necessário, a docente comparecia às reuniões da equipe da ESF como elemento dinamizador do processo de educação permanente desta equipe. Também surgiam as considerações a respeito das atividades que vinham sendo desenvolvidas, como os grupos organizados por eles. Interessante, nesse caso, é perceber como os relatos vinham acompanhados de questionamentos teóricos, dificuldades práticas e, mesmo, das reações diante do que ia acontecendo.

Ao fim do curso, mais uma vez, o diário foi uma peça-chave, agora como ponto de apoio e matériaprima da construção do Trabalho de Conclusão de Curso (TCC). O grupo de residentes voltou aos seus relatos para construir seu trabalho final. Esse retorno às descrições e reflexões se deu pela necessidade de reverem os momentos de imersão no campo, refletindo agora, a partir de um outro lugar, o da academia, sobre situações e enfrentamentos que viveram ao longo da Residência.

\section{Considerações finais}

O diário reflexivo mostrou-se uma ferramenta eficaz que possibilita acompanhar as atividades práticas e a atuação das equipes. Fornece subsídios para avaliação dos estudantes como recurso à reformulação da prática e, sobretudo, propicia o desenvolvimento dos princípios éticos e da relação com os indivíduos e comunidades. Também consiste em um valioso instrumento da gestão educacional da formação em saúde. Propicia ao gestor avaliar o desenvolvimento de competências que extrapolem o cognitivo (saber/ conhecimento e habilidades intelectuais) e o psicomotor (habilidades motoras e manuais), e que incorporem as afetivas (valores e atitudes); possibilita à coordenação do curso ter uma visão ampla das experiências, avaliar o desempenho das equipes de alunos e a construção do aprendizado do residente.

No momento em que os alunos se viram diante do desafio de enfrentar a realidade, o dia a dia da comunidade e do módulo da ESF, seus modos de ver e sentir o cotidiano, ficou clara a importância do 
diário. A dificuldade de se estabelecer harmonia entre 'o como se aprende' e 'o como se faz' valoriza a iniciativa de se pensar um instrumento que, por um lado, está referenciado na antropologia, com seus dados de caráter etnográfico, e, por outro, na educação, como portfólio reflexivo.

Apontamos para a relevância de caminhos pedagógicos que viabilizem uma formação mais ancorada na prática reflexiva baseada em uma postura crítica. No entanto, há a necessidade de aperfeiçoamento dessas experiências e, por isso, a importância do compartilhamento das mesmas, na perspectiva de seu desenvolvimento enquanto processo de conhecimento.

Por fim, cabe ressaltar que o método etnográfico não se reduz a uma técnica. Antes de tudo, como lembra Magnani (2009), é um modo de aproximação e apreensão da realidade, mais do que um conjunto de procedimentos, que oferece a possibilidade para um novo entendimento dessa mesma realidade. Na Saúde, este método vem fortalecer a apreensão de novas experiências de construção compartilhada do conhecimento.

\section{Colaboradores}

Filipe Guterres e Simone Oliveira foram responsáveis pelo trabalho de campo, análise e redação do artigo. Maria Alice Pessanha de Carvalho e Margareth Rose Garcia contribuíram na revisão da versão final do manuscrito.

\section{Referências}

BRASIL. Ministério da Saúde. Secretaria de Gestão do Trabalho e da Educação na Saúde. Departamento de Gestão da Educação na Saúde. Residência multiprofissional em saúde: experiências, avanços e desafio. Brasília, 2006.

CAPRARA, A.; LANDIM, L.P. Etnografia: uso, potencialidades e limites na pesquisa em saúde. Interface - Comunic., Saude, Educ., v.12, n.25, p.363- 76, 2008.

CARVALHO, M.A.P.; GARCIA, M.R.G.; SEIDL, H. Curso de especialização em Saúde da Família nos moldes da residência: desenvolvendo competência para a Atenção Básica. In: BRASIL. Ministério da Saúde. Secretaria de Gestão do Trabalho e da Educação na Saúde. Departamento de Gestão da Educação na Saúde (Org.). Residência multiprofissional em saúde: experiências, avanços e desafio. Brasília, 2006. p.153-70.

DOLORES, A.E.; PEIXINHO, A.L. Avaliação qualitativa em medicina: experiência em propedêutica médica na UFBA, 2003. Rev. Bras. Educ. Med., v.30, n.2, p.20-30, 2006.

FREIRE, P. Pedagogia da autonomia: saberes necessários à prática educativa. 11.ed. São Paulo: Paz e Terra, 1999.

MAGNANI, J.G.C. Etnografia como prática e experiência. Horiz. Antropol., v.15, n.32, p.129-56, 2009.

O velho e bom caderno de campo. Sexta Feira, n.1, p. 8-12, 1997.

MALINOWSKI, B. Os argonautas do Pacífico Ocidental. São Paulo: Abril Cultural, 1998. (Os Pensadores). 
RAYNAUT, C. Interfaces entre a antropologia e a saúde: em busca de novas abordagens conceituais. Rev. Gaecha Enferm, v.7, n.2, p.149-65, 2006.

SÁ-CHAVES, I. (Org.) Os porfólios reflexivos (também) trazem gente dentro: reflexões em torno de seu uso na humanização dos processos formativos. Portugal: Porto Editora, 2005.

SANTOS, F.A. Análise crítica dos projetos político-pedagógicos de dois Programas de Residência Multiprofissional em Saúde da Família. 2010. Dissertação (Mestrado) Escola Nacional de Saúde Pública, Fundação Oswaldo Cruz, Rio de Janeiro. 2010.

SILVA, R.F; SÁ-CHAVES, I. Formação reflexiva: representações dos professores acerca do uso de portfólio reflexivo na formação de médicos e enfermeiros. Interface Comunic., Saude, Educ., v.12, n.27, p.721-34, 2008.

SORDI, M.R.L.; SILVA, M.M. Uso de portfólio na pedagogia universitária: uma experiência em cursos de enfermagem. Interface - Comunic., Saude, Educ, v.14, n.35, p.943-53, 2010.

WEBER, F. A entrevista, a pesquisa e o íntimo, ou por que censurar seu diário de campo? Horiz. Antropol., v.15, n.32, p.157-70, 2009. 
O diário reflexivo foi adotado na Residência Multiprofissional em Saúde da Família da Escola Nacional de Saúde Pública, Fundação Oswaldo Cruz (Ensp/Fiocruz), Rio de Janeiro, Brasil. Durante dois anos acompanhamos uma equipe multiprofissional de três residentes em um módulo da Estratégia de Saúde da Família (ESF), buscando compreender as origens do instrumento no diário de campo da antropologia e no portfólio reflexivo da educação. $O$ instrumento mostrou-se eficaz, possibilitando acompanhar as atividades práticas e a atuação das equipes e fornecendo subsídios para avaliação dos estudantes como recurso para a reformulação da prática; também propicia o desenvolvimento dos princípios éticos e da relação para com os indivíduos e comunidade. No momento em que os alunos se viram diante do desafio de enfrentar a realidade, o dia a dia da comunidade, ficou clara a importância do Diário.

Palavras-chave: Saúde da Família. Diário reflexivo. Trabalho pedagógico em saúde. Antropologia cultural. Portfólio reflexivo.

The experience of reflective diaries in the training process of Multiprofessional Residence in Family Healthcare

Reflective diaries were brought into use for Multiprofessional Residence in Family Health at the National School of Public Health, Oswaldo Cruz Foundation, Rio de Janeiro, Brazil. Over a two-year period, we monitored a multiprofessional team of three residents at a Family Health Strategy module, seeking to understand the origins of this tool in anthropological field diaries and in reflective portfolios within education. The tool was shown to be effective tool and made it possible to monitor the practical activities and operations of teams. It provided support for assessing the students as a resource for reformulation of practice, and for developing ethical principles and relationships with individuals and the community. At the time when the students were faced with the challenge of dealing with reality, i.e. the daily life of the community, the importance of the diary became clear.

Keywords: Family Healthcare. Reflective diary. Pedagogical healthcare work.

Anthropology cultural. Reflective portfolio.

\section{La experiencia de los diarios reflexivos en el proceso de formación de una Residencia Multi-profesional en Salud de la Familia}

Presentamos el diario reflexivo adoptado en la Residencia Multi-profesional en Salud de la Familia de la Escuela Nacional de Salud Pública, Fundación Oswaldo Cruz, Rio de Janeiro, Brasil. Durante dos años seguimos un equipo multi-profesional de tres residentes en un módulo de la Estrategia de Salud de la Familia (ESF), buscando comprender sus orígenes en el diario de campo de la antropología y en el portafolio reflexivo de la educación. La herramienta se mostró eficaz en lo seguimiento de las actividades prácticas y la forma de actuar de los equipos. Provee subsidios para la evaluación de los estudiantes como recurso para la re-formulación de la práctica y de la relación para con los individuos y la comunidad. En el momento en que los alumnos se vieron ante el desafío de afrontar la realidad, el día a día de la comunidad, se quedó clara la importancia del diario.

Palabras clave: Salud de la Familia. Diario reflexivo. Trabajo pedagógico en salud. Antropología cultural. Portafolio reflexivo. 